\title{
Alcoholic and Non-Alcoholic Marchiafava-Bignami Disease: A Comparative Study
}

\author{
Xiaodong Chen ${ }^{1,2 *}$, Yuanwei Wang1, Ying Wang1, Daoming Tong1, Baolin Zhu ${ }^{1}$ \\ ${ }^{1}$ Department of Neurology, Shuyang People's Hospital, Shuyang, China \\ ${ }^{2}$ Graduate School of Southern Medical University, Guangzhou, China \\ Email: *163chenxd@163.com,wyweilmn@126.com,32163393@qq.com, tongdaoming@163.com, \\ 13511775367@163.com
}

Received 8 June 2016; accepted 1 August 2016; published 4 August 2016

Copyright (C) 2016 by authors and Scientific Research Publishing Inc.

This work is licensed under the Creative Commons Attribution International License (CC BY). http://creativecommons.org/licenses/by/4.0/

(c) (i) Open Access

\begin{abstract}
Purpose: Marchiafava-Bignami Disease (MBD) is a rare condition mainly associated with alcoholism, although a few non-alcoholic cases have been reported. We performed a comparative study of demographic and clinical differences between alcoholic and non-alcoholic and assessed whether any treatment can be recommended. Methods: We reviewed 157 reports containing data on 168 subjects with Alcoholic MBD (AMBD) and 23 subjects with Non-Alcoholic MBD (NAMBD). The following data were extracted: demographic characteristics; delay from the onset of symptoms to admission; MRI features; location of the corpus callosum lesions; the presence of Wernicke's disease; drug treatment (thiamine, other vitamins and steroids); outcome. Results: The subjects with AMBD were more frequently men $(84.5 \%$ vs $47.8, P=0.000)$; the ones with AMBD were frequently reported as suffering from malnutrition $(81.3 \%$ vs $50 \%, P=0.019)$, whereas the NAMBD was frequently reported as suffering from diabetes mellitus $(30.4 \%$ vs $7.1 \%, P=0.002)$. The lesions in the NAMBD are often located in the splenium $(47.8 \%)$, whereas single splenial lesions are seen only in $18.7 \%$ of the AMBD. $43.5 \%(10 / 23)$ of the NAMBD was reported to have recovered completely, whereas only $15.4 \%(24 / 156)$ AMBD showed a complete recovery. Conclusions: It is important to diagnose NAMBD in the early stage with MRI and to treat the symptoms with thiamine and/or corticosteroids according to aetiology. We recommend prompt treatment of MBD with parenteral thiamine in subjects associated with malnutrition, anorexia nervosa and prolonged vomiting, and reduction of food intake. Corticosteroids may aid in recovery by reducing oedema in subjects associated with diabetes mellitus.
\end{abstract}

\section{Keywords}

Marchiafava-Bignami Disease, Alcoholism, Malnutrition, Diabetes Mellitus, Prognosis

\footnotetext{
${ }^{*}$ Corresponding author.
}

How to cite this paper: Chen, X.D., Wang, Y.W., Wang, Y., Tong, D.M. and Zhu, B.L. (2016) Alcoholic and Non-Alcoholic Marchiafava-Bignami Disease: A Comparative Study. Neuroscience and Medicine, 7, 99-105. 


\section{Introduction}

Marchiafava-Bignami Disease (MBD) is a rare complication of chronic alcoholism. The main pathological features of MBD are demyelination and necrosis of the corpus callosum. MBD is first reported by Carducci in 1898, and named because two Italian pathologists Marchiafava and Bignami described in detail three patients who had been drinking cheap wine in 1903 [1]. Cause and pathogenesis of MBD remain unclear. It is now generally believed that MBD was strongly associated with effects of alcohol and its metabolites on nutrient metabolism and toxic effect of central nervous system [2]. In this study, Alcoholic MBD (AMBD) includes subjects described either to be chronic current alcoholics or dependent on alcohol and others who were reported to be chronic excessive alcohol consumers with a long history of alcohol abuse or heavy drinking habits.

Even though it was rare, the typical clinical and imaging features of MBD were also found in patients with non-alcohol-related diseases, such as malnutrition, diabetes, exposure to psychoactive substances, hepatitis C, systemic lupus erythematosus, dermatomyositis, malignant tumor, and trauma [3]-[24].

There may be significant differences in the state of an illness, course of disease, treatment response and prognosis of different reasons-induced MBD. This study sought to compare and analyze AMBD and Non-Alcoholic MBD (NAMBD) so as to guide diagnosis and propose to treatment recommendations.

\section{Materials and Methods}

\subsection{Literature Retrieval Strategy and Inclusion Criteria}

We searched PubMed and EMBASE for English, French, Japanese, and Spanish literatures published from January 1975 to March 2015 with "Marchiafava-Bignami disease" in titles or abstracts. The references in retrieved literatures were searched retroactively from the near to the distant according to the year of publication. Two investigators (XDC and BLZ) read the original in detail, and excluded literatures with incomplete abstract, review or data. The same case found in several literatures was considered as one. AMBD is defined as long-term alcohol abuse/large/excessive drinking and/or alcohol dependence. 191 patients from 157 studies were included in this study, including 168 cases of AMBD (one patient was treated by the author, unpublished) and 23 cases of NAMBD.

\subsection{Data Extraction}

Systematic evaluation of data of all patients was done by two investigators (YWW and YW, neurologists Who didn't known the purpose of research) using the blind method. The investigators were trained and assigned to collect information independently on a specifically designed form. Extracted data included age, gender, malnutrition, diabetes mellitus, Wernicke's encephalopathy, time from onset to treatment, MR diagnosis, VitB1 treatment, lesion distribution and prognosis. If the two investigators disagreed with each other, they will be in conference with another investigator (DMT).

\subsection{Statistical Analysis}

Data were analyzed using SPSS 17.0 software and expressed as mean \pm SD. Intergroup comparison was conducted using $t$-test. Numeration data between groups were compared utilizing Pearson $\chi^{2}$ test or Fisher's exact test. Ranked data were compared with Mann-Whitney $U$ test. A value of $P<0.05$ was considered statistically significant.

\section{Results}

\subsection{Comparison of General Data and Clinical Features between the Two Groups}

Compared with the NAMBD patients, most AMBD patients were male ( $84.5 \%$ vs $47.8 \%, P=0.000$ ), had malnutrition ( $81.3 \%$ vs $50 \%, P=0.019$ ), but did not suffer from diabetes ( $7.1 \%$ vs $30.4 \%, P=0.002)$. The average age of AMBD patients was bigger than that of NAMBD patients (50.25 vs 46.08), but the difference was not statistically significant $(P=0.762$ ). Age span was long in NAMBD patients (from 16 to 80 years old). Cortex of most AMBD patients was involved (13.7\% vs 4.3\%), but the difference was not statistically significant between NAMBD and AMBD patients $(P=0.351)$. No significant differences in Wernicke's encephalopathy, time from onset to treatment, VitB1 treatment, and MR diagnosis were detected between the two groups (Table 1). 
Table 1. Demographic and clinical characteristics of subjects with AMBD or non-alcoholic NAMBD.

\begin{tabular}{cccc}
\hline Characteristic & AMBD (n = 168) & NAMBD (n = 23) & $P$ value \\
\hline Mean age at onset, years (95\% CI) & $50.25(48.83-52.16)$ & $46.08(37.62-53.97)$ & 0.762 \\
Men, n (\%) & $142(84.5 \%)$ & $11(47.8 \%)$ & 0.000 \\
Malnutrition (\%) & $65 / 80(81.3 \%)$ & $8 / 16(50.0 \%)$ & 0.019 \\
Diabetes (\%) & $12(7.1 \%)$ & $7(30.4 \%)$ & 0.002 \\
Wernicke's disease (\%) & $17(10.1 \%)$ & $2(8.7 \%)$ & 1.000 \\
Delay from the onset of symptoms to admission $\leq 2$ weeks & $102(60.7 \%)$ & $17(73.9 \%)$ & 0.221 \\
Thiamine treatment (\%) & $119(70.8 \%)$ & $14(60.9 \%)$ & 0.330 \\
MR verification & $158(94.0 \%)$ & $20(87.0 \%)$ & 0.409 \\
Cortical involvement & $23(13.7 \%)$ & $1(4.3 \%)$ & 0.351 \\
\hline
\end{tabular}

\subsection{Comparison of Lesion Distribution between the Two Groups}

Corpus callosum was diffusely involved in 38.8\% AMBD patients, followed by splenium (18.7\%). Only splenium was involved in $47.8 \%$ NAMBD patients. Enhanced magnetic resonance (MR) was performed in 95 AMBD patients, of which 16 cases (16.8\%) affected enhancement. Only five NAMBD patients received enhanced MR, and enhancement was not detected in these patients (Figure 1).

\subsection{Comparison of Prognosis between the Two Groups}

Prognosis was not reported in 12 AMBD patients. The prognosis was significantly better in NAMBD patients than in the remaining AMBD patients $(U=1224, P=0.012)$. The proportion of complete recovery was significantly higher in NAMBD patients than in AMBD patients (43.5\% vs $15.4 \%, P=0.003)$. The proportion of patients with poor prognosis (moderate, severe disability + vegetative state + death) was more in AMBD patients than in NAMBD patients ( $61.5 \%$ vs $26.1 \%, P=0.003$; Table 2 ).

\section{Discussion}

MBD is common in $0.01 \%$ of patients with alcohol-related diseases. To date, no more than 300 cases have been reported in the literature, and most of them suffer from chronic alcoholism [21]. The cause and pathogenesis of MBD are poorly understood. Alcohol intake is strongly associated with MBD. Toxic effects of alcohol and its metabolites can cause demyelination of the corpus callosum. Alcohol-dependent VitB1 deficiency decreased the activities of pyruvate dehydrogenase, alpha ketoacid dehydrogenase and transketolase in the brain, and caused energy metabolism disorder in nerve cells. Elevated blood ammonia induced by chronic alcoholic liver disease probably participates in the pathogenesis of MBD. Alcohol with a small molecular weight, combined with ketoacidosis, noticeably impacted anion gap and osmotic gap, resulted in osmotic myelinolysis [25].

NAMBD is rarer. As far as we know, only 23 cases have been reported since 1979. Possible causes of NAMBD contains: 1) malnutrition: eight patients in this group suffered from NAMBD based on malnutrition. Of them, two cases experienced chronic malnutrition, died after the onset of the short-term loss of caregivers, did not receive cranial CT scan or MR examination, and did not undergo VitB1 replacement therapy. Autopsy confirmed MBD (one case was combined with Wernicke's encephalopathy). It is worth mentioning that above two patients were combined with diabetes [3] [4]. Splenium of corpus callosum was involved in two young female patients with anorexia nervosa. Of them, one patient was intravenously given high doses of fursultiamine (VitB1 derivative), so her symptoms were improved, but the improvement was not obvious. Subsequently, this patient was administered methylprednisolone, so the symptoms were apparently improved. MR reexamination showed that the lesions completely disappeared. The symptoms in another patient were spontaneously recovered [5] [6]. In one case of hyperemesis gravidarum, MR revealed edema in the splenium of corpus callosum, and abnormal signals in the thalamus around the third ventricle, head of caudate nucleus, and insula (Wernicke's encephalopathy); above symptoms were completely improved after administering VitB1 [7]. The splenium of corpus callosum was involved in other three patients with short-term eating disorders, and their prognoses were 

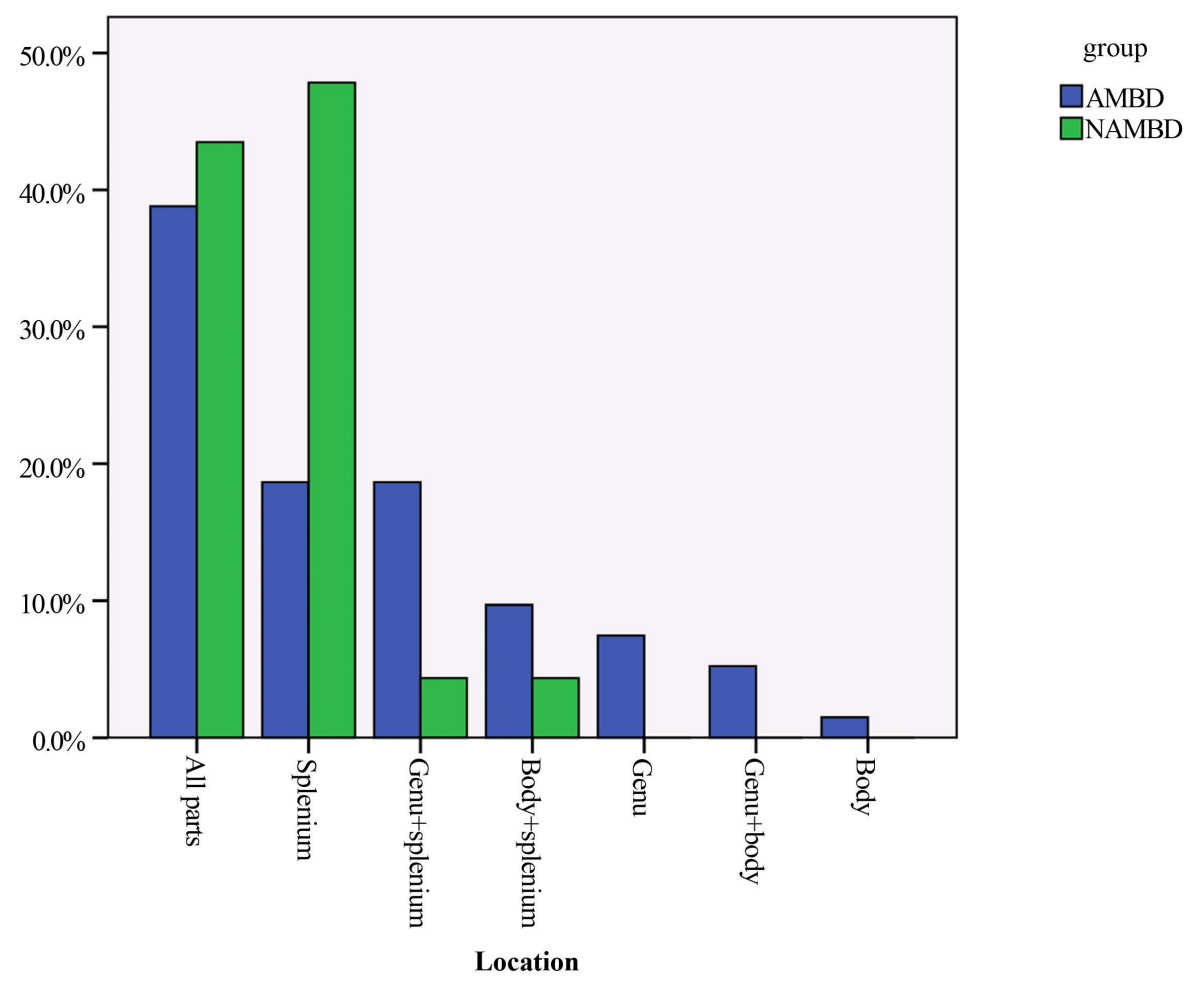

Figure 1. Percentage distribution of callosal lesions among AMBD and NAMBD cases.

Table 2. Outcome on the Glasgow outcome scale for subjects with AMBD or NAMBD.

\begin{tabular}{|c|c|c|c|}
\hline Outcome & $\operatorname{AMBD}(\mathrm{n}=156)^{*}$ & NAMBD $(\mathrm{n}=23)$ & $\begin{array}{l}P=0.012 \\
U=1224\end{array}$ \\
\hline Normal & 24 (15.4\%) & $10(43.5 \%)$ & \multirow[t]{4}{*}{$P=0.003$} \\
\hline Minimal disability & $36(23.1 \%)$ & $7(30.4 \%)$ & \\
\hline Moderate disability & $42(26.9 \%)$ & 0 & \\
\hline Severe disability & $26(16.7 \%)$ & $2(8.7 \%)$ & \\
\hline Vegetative state & $6(3.8 \%)$ & 0 & \multirow{2}{*}{$P=0.003$} \\
\hline Dead & $22(14.1 \%)$ & $4(17.4 \%)$ & \\
\hline
\end{tabular}

*Information on outcome was not available for 12 subjects.

good after administering B vitamins [8]-[10]. 2) Diabetes: seven patients in this group were combined with diabetes, including above-mentioned two patients who died (blood glucose control is unknown). In the remaining five patients, diabetes was not treated; blood glucose control was poor; the fluctuation in blood glucose levels was large; their blood glucose levels were between 214 and $1620 \mathrm{mg} / \mathrm{dL}$ on admission. Of them, the blood glucose levels were between 30 and $450 \mathrm{mg} / \mathrm{dL}$ at 3 months before onset in one case. In one case, blood osmotic pressure reached $392 \mathrm{mosmol} / \mathrm{L}$, lactic acid $3.7 \mathrm{mmol} / \mathrm{L}$, and $\mathrm{pH}$ value of 7.16. In one case, blood sugar was 391 $\mathrm{mg} / \mathrm{dL}$, and glycated hemoglobin was 16\%. In one case, blood glucose was $557.49 \mathrm{mg} / \mathrm{dL}$, serum sodium 124.39 $\mathrm{mmol} / \mathrm{L}$, and blood osmotic pressure $304.9 \mathrm{mosmol} / \mathrm{L}$. The pathological changes were extensive in this group. The entire corpus callosum was diffusely involved in three cases. The splenium of corpus callosum, posterior limb of bilateral internal capsule, and bilateral middle cerebellar peduncles were involved in one case. The splenium of corpus callosum and precentral gyrus were involved in one case [11]-[15]. We presumed that wide fluctuations in blood sugar, frequent significantly hyperglycemia, and hyperosmolar state caused changes in osmotic pressure in glial cells, structural and functional changes similar to the "central pontine myelinolysis". In 
addition, studies have found compared with healthy controls, plasma VitB1 decreased by 75\% and VitB1 transporter 1 was apparently increased in diabetes patients. Regrettably, this group did not conduct VitB1 metabolism-related examination. The effect of VitB1 metabolism on pathogenesis of MBD deserves further investigations. Although the lesion is widespread, the prognosis of diabetes-related MBD is good. On the basis of stabilizing blood glucose, three patients in this group were subjected to corticosteroid therapy (two patients were given B vitamins), their symptoms were gradually relieved: complete recovery or only mild neurological disorders. Two patients only received symptomatic treatment, without corticosteroid or VitB1), and recovery was substantially complete. 3) Exposure to psychoactive substances: one depression patient took diazepam, venlafaxine and trazodone by himself, and had aggressive behavior after drug withdrawal. MR revealed diffuse involvement of the corpus callosum. One patient exposed to acetone and butanone during his work for 14 years, and gradually experienced disturbance of intelligence. MR showed the involvement of anterior and posterior parts of the corpus callosum. One patient took cannabis, and was insensible due to unknown trauma. MR demonstrated the involvement of splenium and body of corpus callosum. The prognosis was poor in this group. The symptoms were improved after adjusting antidepressants in one case, but he had mild neurological disorders. In one case, VitB1 was ineffective, but corticosteroid was effective for a short time, but the symptoms were returned to baseline levels soon. In one case who took a high dose of VitB1, the symptoms were improved, but severe disability still existed [16] [17] [22]. 4) Hepatitis C: This group contained one case of chronic Hepatitis C, involving entire corpus callosum and bilateral internal capsule, and one case of hepatitis C, cirrhosis and peritonitis, involving splenium of corpus callosum. Their prognoses were good after treatment with VitB1 [16] [18]. Studies confirmed that in alcoholics for a long period, severe hepatic dysfunction and elevated blood ammonia could lead to encephalopathy, corpus callosum edema, and demyelination. We presumed that the pathogenesis of the two patients may be similar to above results. 5) Autoimmunity and infection: one case affected the central nervous system lupus, MR demonstrated that edema of the entire corpus callosum was recovered completely after corticosteroid treatment. One case combined with SC hemoglobinopathy and cerebral malaria. MR revealed low signal intensity in the splenium of corpus callosum on $\mathrm{T} 2 *$ susceptibility weighted imaging, indicating bleeding. Authors considered that it was severe vascular obstruction, which was recovered completely after administration of quinine and VitB1 [19] [20]. 6) Malignant tumor: one case of ovarian cancer at stage IV did not have indications for surgery or receive chemotherapy, but affected sudden loss of consciousness. MR exhibited the involvement of corpus callosum and bilateral dentate nucleus. No enhancement occurred. Treatment with B vitamins and methylprednisolone was ineffective. Three days later, this case died of respiratory failure. We believed that it was paraneoplastic syndrome [21]. 7) Others: one case of syphilis died from subacute endocarditis, but autopsy found MBD by chance [23]. One 42-year-old male patient suffered from sudden coma for no apparent reason. Cranial MR displayed extensive damage to corpus callosum and periventricular white matter [24].

Although MBD seems to carry prospects of a better outcome now than before, the prognosis is still not good. Since the outcome of MBD is variable, it is important to look for hints on how to treat the disease. Hillbom M and colleagues [26] reviewed published case reports from 1981 to 2012. In 153 AMBD cases were analysed, there was a significant linear trend for better outcomes among those who were treated with thiamine, whereas treatment with steroids did not show any significant trend. The outcome of the subjects who were given thiamine in the acute phase of the disease was significantly better than that of those treated in the chronic phase. We observed VitB1 and corticosteroid are the most commonly used empirical treatment of NAMBD besides symptomatic and supportive treatments. The therapeutic effect of VitB1 is good in patients combined with short-term malnutrition and hepatitis C. The therapeutic effect of corticosteroid is good in patients combined with diabetes-related diseases. Nevertheless, because the disease is rare, etiology and pathogenesis are not clear, we yet cannot give treatment recommendations. Compared with AMBD, NAMBD could only be detected in the splenium of corpus callosum (50\%). Among 11 patients, 7 patients merely suffered from the injury to the splenium of corpus callosum (no damage to the tissue surrounding the corpus callosum), and their prognoses were good. Three patients combined with injures to the posterior limb of the internal capsule, brachium pontis, precentral gyrus, and thalamus, and their prognoses were good. Only one case combined with extensive damage to periventricular white matter affected severe disability [24]. These results suggest that the lesion limited in the splenium of corpus callosum was a predictor of good prognosis. A previous study discussed that patients with AMBD involved in the white matter and cortex outside the corpus callosum had a poor prognosis [27]. This study verified that the lesion was extensive in patients with diabetes-related non-dystrophic MBD, but the prognosis was good. 


\section{Conclusion}

We would like to make two recommendations based on our review. First, it is important to diagnose NAMBD in the early stage with MRI and to treat the symptoms with thiamine and/or corticosteroids according to aetiology. Second, prompt treatment of MBD with parenteral thiamine in subjects associated with malnutrition, anorexia nervosa and prolonged vomiting, and reduction of food intake seems to be indicated. Corticosteroids may aid in recovery by reducing edema in subjects associated with diabetes mellitus.

\section{References}

[1] Marchiafava, E. and Bignami, A. (1903) Sopra un alterazione del corpo calloso osservata in soggetti alcoolisti. Rivista di Patologia Nervosa e Mentale, 8, 544-549.

[2] Brust, J.C. (2010) Ethanol and Cognition: Indirect Effects, Neurotoxicity and Neuroprotection: A Review. International Journal of Environmental Research and Public Health, 7, 1540-1557. http://dx.doi.org/10.3390/ijerph7041540

[3] Rickert, C.H., Karger, B., Varchmin-Schultheiss, K., Brinkmann, B. and Paulus, W. (2001) Neglect-Associated Fatal Marchiafava-Bignami Disease in a Non-Alcoholic Woman. International Journal of Legal Medicine, 115, 90-93. http://dx.doi.org/10.1007/s004140100233

[4] Leong, A.S. (1979) Marchiafava-Bignami Disease in a Non-Alcoholic Indian Male. Pathology, 1, 241-249. http://dx.doi.org/10.3109/00313027909061950

[5] Tao, H., Kitagawa, N., Kako, Y., Yamanaka, H., Ito, K., Denda, K. and Koyama, T. (2007) A Case of Anorexia Nervosa with Marchiafava-Bignami Disease That Responded to High-Dose Intravenous Corticosteroid Administration. Psychiatry Research, 156, 181-184. http://dx.doi.org/10.1016/j.pscychresns.2007.04.013

[6] Maki, N., Hokoishi, K., Komori, K. and Tanabe, H. (2001) A Case of Marchiafava-Bignami Disease Caused by Anorexia Nervosa. No To Shinkei, 53, 669-671.

[7] Hillbom, M., Pyhtinen, J., Pylvänen, V. and Sotaniemi, K. (1999) Pregnant, Vomiting, and Coma. Lancet, $353,1584$. http://dx.doi.org/10.1016/S0140-6736(99)01410-5

[8] Cui, Y., Zheng, L., Wang, X., Zhang, W., Yuan, D. and Wei, Y. (2015) Marchiafava-Bignami Disease with Rare Etiology: A Case Report. Experimental and Therapeutic Medicine, 9, 1515-1517.

[9] Furukawa, K., Maeshima, E., Maeshima, S. and Ichinose, M. (2011) Multiple Symptoms of Higher Brain Dysfunction Caused by Marchiafava-Bignami Disease in a Patient with Dermatomyositis. Rheumatology International, 31, 109112. http://dx.doi.org/10.1007/s00296-009-1164-4

[10] Rusche-Skolarus, L.E., Lucey, B.P., Vo, K.D. and Snider, B.J. (2007) Transient Encephalopathy in a Postoperative Non-Alcoholic Female with Marchiafava-Bignami Disease. Clinical Neurology and Neurosurgery, 109, 713-715. http://dx.doi.org/10.1016/j.clineuro.2007.05.005

[11] Pérez Álvarez, A.I., Ramón Carbajo, C., Morís de la Tassa, G. and Pascual Gómez, J. (2015) Marchiafava-Bignami Disease Triggered by Poorly Controlled Diabetes Mellitus. Neurologia.

[12] Yadala, S. and Luo, J.J. (2013) Marchiafava-Bignami Disease in a Nonalcoholic Diabetic Patient. Case Reports in Neurological Medicine, 2013, Article: 979383. http://dx.doi.org/10.1155/2013/979383

[13] Suzuki, Y., Oishi, M., Ogawa, K. and Kamei, S. (2012) A Patient with Marchiafava-Bignami Disease as a Complication of Diabetes Mellitus Treated Effectively with Corticosteroid. Journal of Clinical Neuroscience, 19, 761-762. http://dx.doi.org/10.1016/j.jocn.2011.07.040

[14] Hlaihel, C., Gonnaud, P.M., Champin, S., Rousset, H., Tran-Minh, V.A. and Cotton, F. (2005) Diffusion-Weighted Magnetic Resonance Imaging in Marchiafava-Bignami Disease: Follow-Up Studies. Neuroradiology, 47, 520-524. http://dx.doi.org/10.1007/s00234-005-1368-6

[15] Kilinc, O., Ozbek, D., Ozkan, E. and Midi, I. (2015) Neurological and Psychiatric Findings of Marchiafava-Bignami Disease in a Nonalcoholic Diabetic Patient with High Blood Glucose Levels. Journal of Neuropsychiatry \& Clinical Neurosciences, 27, e149-e150. http://dx.doi.org/10.1176/appi.neuropsych.14030056

[16] Caulo, M., Briganti, C., Notturno, F., Committeri, G., Mattei, P.A., Tartaro, A., et al. (2009) Non-Alcoholic Partially Reversible Marchiafava-Bignami Disease: Review and Relation with Reversible Splenial Lesions. A Case Report and Literature Review. The Neuroradiology Journal, 22, 35-40. http://dx.doi.org/10.1177/197140090902200106

[17] Murthy, S.B., Jawaid, A., Bock, J.E., Qureshi, S.U. and Schulz, P.E. (2010) Marchiafava-Bignami Disease (MBD) in a Nonalcoholic Patient: A Case Report. The Canadian Journal of Neurological Sciences, 37, 138-140. http://dx.doi.org/10.1017/S0317167100009823

[18] Ménégon, P., Sibon, I., Pachai, C., Orgogozo, J.M. and Dousset, V. (2005) Marchiafava-Bignami Disease: DiffusionWeighted MRI in Corpus Callosum and Cortical Lesions. Neurology, 65, 475-477. 
http://dx.doi.org/10.1212/01.wnl.0000171348.55820.89

[19] Kashiwagi, Y., Horiuchi, T., Harashima, C., Matsubara, F. and Harashima, S. (2010) Marchiafava-Bignami DiseaseLike Lesions Due to Central Nervous System Lupus. BMJ Case Reports, bcr0820103269. http://dx.doi.org/10.1136/bcr.08.2010.3269

[20] Boutboul, D., Lidove, O., Aguilar, C., Klein, I. and Papo, T. (2010) Marchiafava-Bignami Disease Complicating SC Hemoglobin Disease and Plasmodium falciparum Infection. La Presse Médicale, 39, 990-993. http://dx.doi.org/10.1016/j.lpm.2010.02.052

[21] Celik, Y., Temizoz, O., Genchellac, H., Cakir, B. and Asil, T. (2007) A Non-Alcoholic Patient with Acute Marchiafava-Bignami Disease Associated with Gynecologic Malignancy: Paraneoplastic Marchiafava-Bignami Disease? Clinical Neurology and Neurosurgery, 109, 505-508. http://dx.doi.org/10.1016/j.clineuro.2007.02.011

[22] Jorge, J.M., Gold, M., Sternman, D., Prabhakaran, K. and Yelon, J. (2015) Marchiafava-Bignami Disease in a Trauma Patient. Journal of Emergencies, Trauma, and Shock, 8, 52-54. http://dx.doi.org/10.4103/0974-2700.150399

[23] Ma, K.C. and Chen, K.J. (1983) Primary Necrosis of Corpus Callosum with Dystrophic Astrogliosis and RosenthalLike Fiber Formation. The First Chinese Case of Marchiafava-Bignami’s Disease (MBD). Acta Neuropathologica, 60, 283-290. http://dx.doi.org/10.1007/BF00691878

[24] Tozakidou, M., Stippich, C. and Fischmann, A. (2011) Teaching Neuroimages: Radiologic Findings in MarchiafavaBignami Disease. Neurology, 77, e67. http://dx.doi.org/10.1212/wnl.0b013e31822e144b

[25] Thomson, A.D., Guerrini, I. and Marshall, E.J. (2012) The Evolution and Treatment of Korsakoff's Syndrome: Out of Sight, Out of Mind? Neuropsychology Review, 22, 81-92. http://dx.doi.org/10.1007/s11065-012-9196-z

[26] Hillbom, M., Saloheimo, P., Fujioka, S., Wszolek, Z.K., Juvela, S. and Leone, M.A. (2014) Diagnosis and Management of Marchiafava-Bignami Disease: A Review of CT/MRI Confirmed Cases. Journal of Neurology, Neurosurgery \& Psychiatry, 85, 168-173. http://dx.doi.org/10.1136/jnnp-2013-305979

[27] Wenz, H., Eisele, P., Artemis, D., Förster, A. and Brockmann, M.A. (2014) Acute Marchiafava-Bignami Disease with Extensive Diffusion Restriction and Early Recovery: Case Report and Review of the Literature. Journal of Neuroimaging, 24, 421-424. http://dx.doi.org/10.1111/j.1552-6569.2012.00755.x

\section{Submit or recommend next manuscript to SCIRP and we will provide best service for you:}

Accepting pre-submission inquiries through Email, Facebook, LinkedIn, Twitter, etc.

A wide selection of journals (inclusive of 9 subjects, more than 200 journals)

Providing 24-hour high-quality service

User-friendly online submission system

Fair and swift peer-review system

Efficient typesetting and proofreading procedure

Display of the result of downloads and visits, as well as the number of cited articles

Maximum dissemination of your research work

Submit your manuscript at: http://papersubmission.scirp.org/ 